International Journal of Instruction e-ISSN: 1308-1470 • www.e-iji.net
April 2019 • Vol.12, No.2

p-ISSN: 1694-609X

pp. 227-242

Received: 30/07/2018

Revision: 08/12/2018

Accepted: 22/12/2018

OnlineFirst:06/03/2019

\title{
Comparative Analysis of Auditory Perception based on Educational Background Differences
}

\section{Pasit Leeniva}

Dr., corresponding author, School of Architecture, Bangkok University, Bangkok, Thailand,pasit.l@bu.ac.th

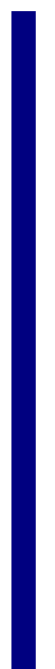

This research study is an experimental study focusing on auditory perception. The objectives of this research are (1) to evaluate acoustical characteristics of the classroom (2) to assess acoustical perceptions of students with different educational backgrounds. The subjects of this study consisted of 54 science students and 53 art students. The control variable is the Percentage of Absorbing Surface (PAS) inside the classroom. The first procedure of experiment was to simulate a lecture speech from a sound generator, with the adjustment of the sound absorbing surface between five levels of PAS: 0, 7.5, 15f, 15b, and 30. Next, the participants were asked to complete a questionnaire to evaluate their auditory perception according to three main areas: loudness, clearness, perceived reverberation. Then, the results were compared with the outcome from a sound test device. The findings revealed that overall there was no difference between two groups of students in their auditory perceptions. However, when the results according to the different levels of PAS were thoroughly investigated, it was found that the science students rated their auditory perception of loudness and clearness higher than the art students who rated theirs when they were in the room with the PAS above $15 \%$.

Keywords: acoustical environment, auditory perception, educational background, sound absorbing surface

\section{INTRODUCTION}

The acoustical environment caused by the physical environment inside the room consists of the floor, wall, ceiling, furniture, decorated equipment, and the surface covered materials with different acoustic qualities (Astolfi et al., 2008). Nowadays, many of the classrooms are in the condition classified as 'poor acoustics' (Zannin \& Marcon, 2007). Poor acoustics classrooms are most commonly found in public universities because these rooms were designed for easy cleaning and maintenance. These classrooms can be spotted by using a selection of smooth polished floor surface. This type of classroom designs can have negative effects on the acoustical environment (Leeniva \& Upala,

Citation: Leeniva, P. (2019). Comparative Analysis of Auditory Perception based on Educational Background Differences. International Journal of Instruction, 12(2), 227-242. https://doi.org/10.29333/iji.2019.12215a 
2017b). The most common problem found is a reverberant condition which decreases sound quality. However, the sound absorbing materials frequently found in almost all of the classrooms are curtains or light-filtering materials around the window area. The capability of sound absorption depends on the sound absorbing surface within the room or the Percentage of Absorbing Surface (PAS) (Fuchs et al., 2001).

The adjustment of PAS will affect the acoustic characteristics of the room which in turn will result in the perception of people in the room (Leeniva \& Upala, 2017a). The sound perception of people in this environment is the main issue being studied together with the assessment of the acoustical measurement through a sound analyzing device (Zannin $\&$ Marcon, 2007). Since perceptions of each individual are varied depending upon personal factors such as educational backgrounds, any spatial design must consider its suitability for particular users. For classrooms, what important the most are the differential educational backgrounds of the students who would be the users of each particular classroom. Therefore, an acoustical environment suitable for users could account for effective teaching and learning. This idea leads to the research conceptual framework and the research objectives as shown in Figure 1. The research objectives are (1) to evaluate acoustical characteristics of the classroom (2) to assess acoustical perceptions of the students with different educational backgrounds

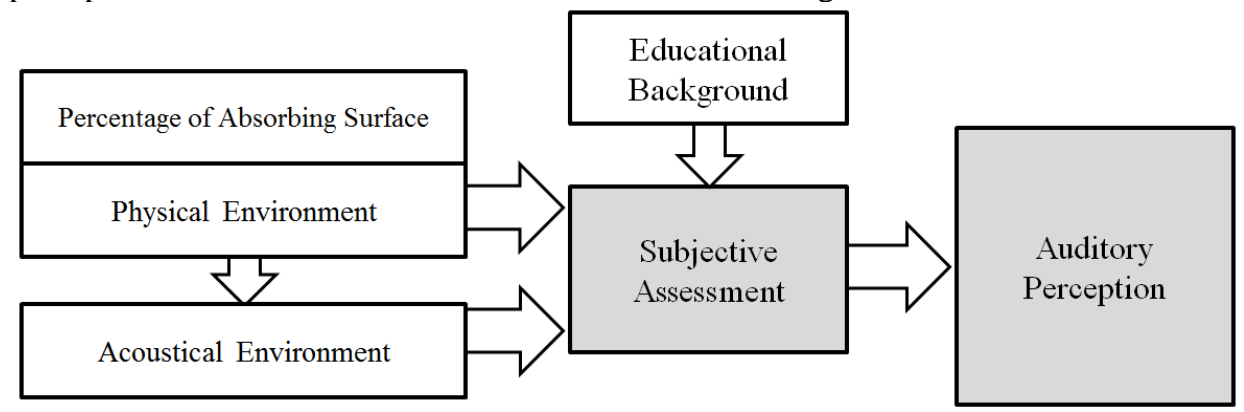

Figure 1

Research conceptual framework

\section{LITERATURE REVIEW}

\section{Auditory Perception of Students with Different Educational Backgrounds}

Auditory perception is the assessment of sound characteristics as perceived by human beings. It is a part of the psychoacoustics approach which integrates the concept of subjective and objective evaluation. An assessment of the acoustical environment by individuals plays an important role in determining an appropriate approach in addition to measurement using analytical sound instruments (Asutay et al., 2012). It also includes psychological and emotional aspects. Zannin and Marcon (2007) conducted a subjective acoustical evaluation of teachers and students' perceptions in comparison with an objective evaluation by measuring the Background Noise Level (BNL) and the Reverberation Time (RT). The results of the study revealed that both of the evaluations were consistent. In addition, the sample group also commented that noise interrupts their 
concentration which in turn negatively affects teaching efficiency and also impacted speech intelligibility. Similarly, Klatte and Hellbruck (2010) investigated the effects of sound environment and RT. they found out that excessive RT ( $>1.10$ seconds) was categorized as part of the characteristics of 'poor acoustics' classrooms, which negatively affected students' reading ability and the relationship between teachers and students including students' negative attitudes towards school.

However, there are some studies which mention different personal factors affecting different perceptions (Olson, 1967). Educational background factor is one factor contributing to different perceptions in individuals. In terms of auditory perceptions, students majoring in art are more sensitive to hearing than the students majoring in science (Fasanya et al., 2011). It seems that art students would have better perceptions of the volume level adjustments than the science students. While the science students would focus more on the clarity of the preferred sound. The results of these studies will lead to appropriate classroom management approaches in line with the educational backgrounds of the students in each group.

\section{The Sound-absorbing Performance and The Acoustical Environment in Classroom}

The acoustical environment is an important factor in the classroom environment because if the learner does not hear the lecture clearly, it will have a negative impact on the learning process (Leeniva \& Upala, 2015). The composition of the acoustical environment in the room is composed of sound reflection and sound absorption (Egan, 1972). Reflection will be heard throughout the room and it will boost the volume at locations which are far from the sound sources. On the other hand, the reflection of sound will cause background noise level or ambient sound rises (Cabanaugh \& Wikes, 1998). Sound absorption plays a role in reducing noise and enhancing the sound of the speech to be clearer (Sala \& Viljanen, 1995).

The key indexes for assessing the acoustical environment within the classroom are the Background Noise Level (BNL), the Reverberation Time (RT), and the Speech Transmission Index (STI) (Bradley, 1986a; Bradley, 1986b; Hodgson, 1999; Bistafa \& Bradley, 2000). The sound standard for the classroom of each index is BNL $=35-40$ $\mathrm{dBA}, \mathrm{RT}=0.7-1.2 \mathrm{~s}$ and STI=>0.6 (ANSI S12.60, 2002; Tang \& Yeung, 2003; IEC 60268-16, 2011). All three indexes are interrelated. High level of BNL and RT will affect the clarity of the speech. When the room is very resonant, the level of clarity will become lower (Tang \& Wong, 1998).

The key factor determining these indexes is the sound absorbing surface area in the room. The sound absorbing surface inside the room is an important part that reduces the background noise level and the resonance. It will contribute to the level of clarity within the classroom (Leeniva \& Upala, 2017). Concordantly, the study of Sala and Viljanen (1995) claimed that in the classroom, there should be $30 \%$ of sound absorption in the room and at least two sides on the wall, resulting in good speech clarity (STI=0.75). According to the standardization of the Acoustical Society of America (2002), it states that the result of RT for a large classroom should not be over 0.7 seconds. The main factors of sound reflection are the capacity of the room and the ability to absorb sound. 
Therefore, the absorbing surface should be installed at the wall or ceiling for the quality of the acoustical environment within the classroom.

\section{METHOD}

\section{This research study consists of four steps:}

Step-1---Preparation for testing: A proper room area was selected for the experiment. The room area selected was capable for the adjustment of the Percentage of Absorbing Surface (PAS) from 0-30\% by simulated-sound testing from a loudspeaker to control the loudness level factor in the same pattern.

Step-2---Room acoustical measurement: It was the assessment of the sound environment when the physical environment changed by adjusting PAS in five levels. The indexes used in the evaluation were SPL, STI, and RT. The indexes were compared with the auditory perception in terms of loudness, clearness, and reverberation.

Step-3---Questionnaire survey: This step was to evaluate the students' attitudes towards the auditory perception by using a five-scale questionnaire with the rating scale ranging from 1 which means strongly disagree and 5 which means strongly agree. The students were asked to assess their auditory perception in three main areas; loudness, clearness, and reverberation. The participants in the experiment were divided into two groups: the science and the art students. Data were collected within two days under the same condition and the number of the students was limited in class.

Step-4---Data analysis and conclusion: The data analysis was done by using the inferential statistics--- t-test to compare the attitudes and the auditory perceptions of the two sample groups. Later, the statistical analysis led to the final research findings

\section{Research Variables}

There were three main variables in this research: independent, dependent and controlled variable as shown in Table 1. 
Table 1

The research variables

\begin{tabular}{|c|c|c|c|}
\hline Variables & Conceptual variables & Operational variables & Indicators \\
\hline 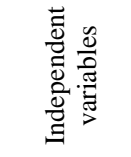 & Sounds for testing & $\begin{array}{l}\text { Lecture } \\
\text { Impulse noise } \\
\text { STI signal for test }\end{array}$ & $\begin{array}{l}\text { Teacher lecturing class } \\
\text { The sound of the balloon burst } \\
\text { STIPA signal }\end{array}$ \\
\hline \multirow{2}{*}{ 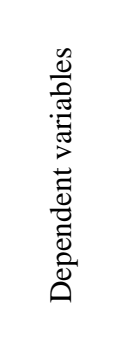 } & $\begin{array}{l}\text { Room-acoustical } \\
\text { environment }\end{array}$ & $\begin{array}{l}\text { Acoustical } \\
\text { characteristics in room }\end{array}$ & $\begin{array}{l}\text { Background Noise Level (BNL) with } \\
\text { A/C: decibel (dBA) } \\
\text { Sound Pressure Level (SPL): decibel } \\
\text { (dBA) } \\
\text { Reverberation Time (RT): second } \\
\text { Speech Transmission Index (STI): 0-1 }\end{array}$ \\
\hline & Auditory perception & Subjective assessment & $\begin{array}{l}\text { Users satisfaction (level 1-5) } \\
\text { - Perceived loudness } \\
\text { - Perceived clearness } \\
\text { - Perceived reverberation }\end{array}$ \\
\hline \multirow{4}{*}{ 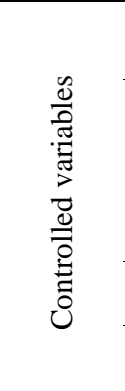 } & Absorbing surface & $\begin{array}{l}\text { Percentage of Absorbing } \\
\text { Surface (PAS) }\end{array}$ & PAS: $0 \%, 7.5 \%, 15 \% \& 30 \%$ \\
\hline & Sounds for testing & Characteristics of sounds & $\begin{array}{l}\text { Sound level: Intensity and loudness } \\
\text { - Lecture : BNL + } 15 \mathrm{dBA} \\
\text { - Balloon burst : BNL + } 60 \mathrm{dBA} \\
\text { - STIPA signal : BNL + } 15 \mathrm{dBA} \\
\text { Flatted sound (no color, no effects) }\end{array}$ \\
\hline & Human factors & Personal information & $\begin{array}{l}\text { Educational background } \\
\text { (controlled groups: Science and Art) }\end{array}$ \\
\hline & Physical environment & $\begin{array}{l}\text { Classroom-physical } \\
\text { environment }\end{array}$ & Large classroom (288-566 cubic meter) \\
\hline
\end{tabular}

\section{Recruitment of the Classroom for Experimentation}

The research objective aimed to evaluate and compare the auditory perceptions on reverberant condition, sound clearness, and sound quality of students with different educational backgrounds between the science and the art students in a lecturing classroom with the sound absorption adjusted. The classroom chosen for this experiment was quite big or could contain 100-120 students. It is more likely that the reverberant conditions would occur in this type of room than in a smaller room (ANSI, 2002; Paradis, 2014)

The experimental area was selected by the purposive sampling technique. The criteria for the area selection were as follows (1) it must be a large classroom with its volume 288-566 meter cube according to ANSI standard (2) the room must be used for lecturing only (3) the room must be adjustable. It must be capable to absorb the sound by adjusting the curtains to have the surface area volume from $0-30 \%$ of the whole area of the room (4) it must be a classroom in the traditional shoebox shape (5) the room must have a closed environment and must be equipped with air conditioners. 


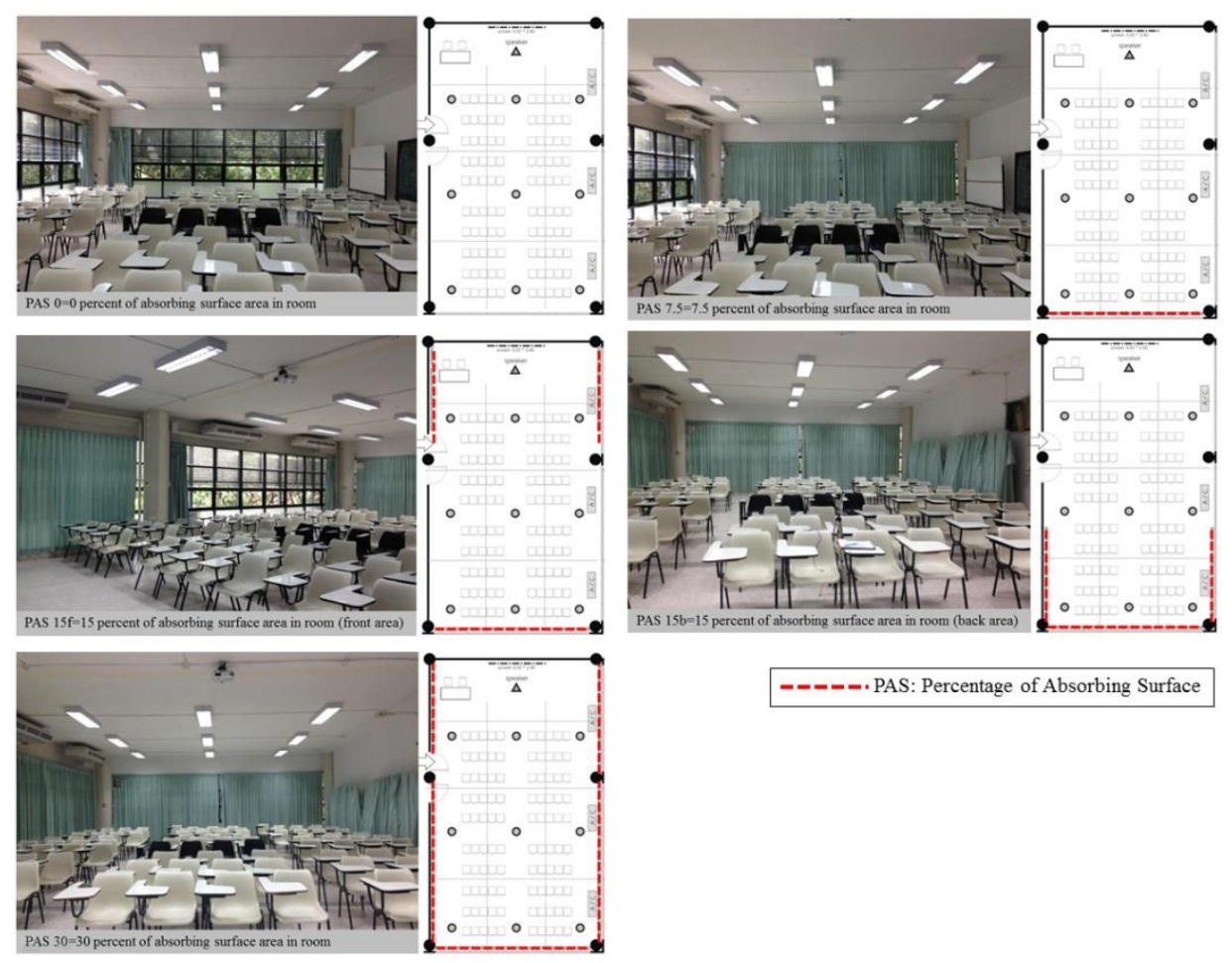

Figure 2

The floor plan of the experimental room with the five-level PAS

The experimental room used for lecturing is located in the Learning Center Building, Faculty of Architecture at King Mongkut's Institute of Technology Ladkrabang (KMITL), with the capability of the 428.34 cubic meters (wide 8.80 meters, deep 14.75 meters, and high 3.30 meters) and is a rectangle large classroom according to ANSI. The surface-covering materials in the room were the selection of the materials which were easy for maintenance such as polishing surface tiles, flat gypsum ceiling, and walls. All of these materials contribute to the sound absorption performance in the room equals to zero (Larm et al., 2004; Leeniva \& Upala, 2017a). As in Figure 2, the classroom floor plan of with the PAS in five levels: PAS 0, PAS 7.5, PAS 15, and PAS 30. In terms of the PAS of $15 \%$, it was divided into two patterns: $15 \%$ in the front area (PAS 15f) and $15 \%$ in the back area (PAS $15 b)$.

\section{Sound Simulation for Testing}

The sound used in the test was the lecturing sound which was created by the spoken sound simulation program, jRaja-VAJA v.6.0 (Home edition) of NECTEC, Thailand. The sound pattern was similar to the real speaking of the lecturer without emotional information. The sound from loudspeakers doesn't transmit any reverb, delay and plugin effects. The lecture sound took about one minute per one testing in order to evaluate 
the sound perception of the participants in three aspects: loudness, clearness, and reverberation. Apart from the lecturing-speech sound, the other sound simulation was tested by a measuring device, RT using the impulse noise in the form of balloon burst at the loudness of $60 \mathrm{dBA}+$ Background Noise Level (BNL+60 dBA). For example, if the room has the BNL $40 \mathrm{dBA}$, the balloon burst loudness will be at $100 \mathrm{dBA}$. For the measuring STI, the STIPA signal was used at the loudness of BNL+15 dBA.

\section{Participants}

Through cooperation with the Student Union of KMITL, one hundred and seven undergraduate students were voluntarily recruited to take part in this experiment. They all had the normal hearing. The main variable was their educational backgrounds. The participants were equally divided into two groups. The first group consisted of 54 science students from Faculty of Engineer, Science, and Architecture. The second group consisted of 53 art students from Faculty of Architecture and Faculty of Administration \& Management. The participants ranged in age from 18-21 years old, $43 \%$ of the participants were males and $57 \%$ of the participants were females. They were studying in different years ranging from year 1 to year 4.

\section{Questionnaire for Auditory Perception}

The questionnaire to evaluate the participants' sound perception was divided into three parts as follows: Part 1 asks the participants about their personal information which includes personal information; educational background (science or art), gender, age, study level and the faculty. Part 2 asks about their auditory perception. The participants were asked to use the provided 5 rating scale ranging from 1 (strongly disagree) to 5 (strongly agree) to rate their auditory perceptions on the three main areas: loudness, clearness and perceived reverberation. The participants were asked to rate their perceptions after the PAS in the classroom was adjusted and the testing sound was on. Part 3 asks the participants to evaluate their satisfaction. This part is an evaluation of overall patterns on the sound perception through the question--- "Which is the most appropriate pattern of sound (PAS level) for a lecture classroom?".

\section{Room Acoustical Measurement}

The room acoustical characteristics were indicated in three acoustical indexes: Background Noise Level (BNL), Reverberation Time (RT), and Speech Transmission Index (STI) (Zannin \& Marcon, 2007). These indexes have been used to establish the standard in many counties such as America, Germany, France or Brazil. In Thailand, Department of Pollution Control has adopted the ANSI S12.60 standard of America. The sound indicator standard for a large classroom is shown in Table 2. 
Table 2

The sound standard indicator of the large classroom

\begin{tabular}{llll}
\hline Acoustical indexes & Value & Standards & Years of definition \\
\hline Background Noise Level (BNL) & $35-40 \mathrm{dBA}$ & ANSI S12.60 & 2002 \\
\hline Reverberation Time (RT) & $\leq 0.7$ second & ANSI S12.60 & 2002 \\
\hline Speech Transmission Index (STI) & $\geq 0.60$ & IEC 60268-16 ed.4 & 2011 \\
\hline
\end{tabular}

The measurement of BNL RT and STI has analyzed via the smartphone applications called SLA (Sound Level Analyzer) APM tool and iSTI respectively. The sound value was evaluated through the Calibrated Measurement Microphone (Dayton iMM-6). The reference to the international standard of the application and the microphone passing the international standard set by International Electrotechnical Commission (IEC). The other devices used in data collection consisted of the adjustable leg for microphone and speaker, anti-wind sponge, note-taking form, computer and smartphone (iphone $5 \mathrm{~s}$, iOS version 9.3).

The guidelines for the equipment installation of a sound generator and the sound measuring point were referred from the lecturer's standing teaching point that was at the middle front of the room at the high level of 1.50 meters. The equipment position of the receiving point was at students' ear level while they were sitting and listening to the lecturing which was 1.20 meters by setting 9 scattering points over the room points and with 1 meter far from the wall of the point closed to the wall. The time of data collection was in the daytime with all the doors closed and the air conditioners were on. There were no students and activities in the adjunct areas on that day of the experiment. The weather condition was clear with no rain, thunder, and wind.

\section{The Classroom with Five Levels of PAS}

Table 3 illustrates the acoustical characteristics evaluation of the classroom after the PAS was adjusted in five levels. The acoustical characteristics values were shown in the mean score of the four acoustical indexes consisting of BNL, SPL, STI, and RT when the lecture sound was turned on.

Table 3

Room-acoustical characteristics when PAS in the room adjusted

\begin{tabular}{|c|c|c|c|c|}
\hline $\begin{array}{l}\text { PAS: } \\
\text { Percentage of } \\
\text { Absorbing } \\
\text { Surface }\end{array}$ & $\begin{array}{l}\text { BNL: } \\
\text { Background } \\
\text { Noise Level } \\
\text { (dBA) }\end{array}$ & $\begin{array}{l}\text { STI: } \\
\text { Speech } \\
\text { Transmission } \\
\text { Index }(0-1)\end{array}$ & $\begin{array}{l}\text { RT: } \\
\text { Reverberation } \\
\text { Time } \\
\text { (second) }\end{array}$ & $\begin{array}{l}\text { SPL: Sound } \\
\text { Pressure Level } \\
\text { with lecture sound } \\
\text { (dBA) }\end{array}$ \\
\hline & $\bar{x}$ [min.-max.] & $\bar{x}$ [min.-max.] & $\bar{x}$ [min.-max.] & $\bar{x}$ [min.-max.] \\
\hline PAS 0 & 44.9 [44.1-45.7] & $0.48[.44-.54]$ & 1.39 [1.13-1.52] & 77.83 [76.7-79.5] \\
\hline PAS 7.5 & 44.5 [44.0-44.9] & $0.54[.50-.61]$ & $1.16[.90-1.33]$ & 77.32 [76.0-79.2] \\
\hline PAS $15 f$ & $43.9[43.0-45.5]$ & $0.56[.51-.63]$ & $0.95[.74-1.06]$ & $76.58[74.3-79.6]$ \\
\hline PAS $15 b$ & 44.1 [42.8-44.9] & $0.55[.50-.64]$ & $0.94[.74-1.05]$ & 76.60 [74.7-78.5] \\
\hline PAS 30 & $43.6[43.0-44.60]$ & $0.59[.54-.66]$ & $0.69[.61-.86]$ & $76.02[74.0-79.0]$ \\
\hline
\end{tabular}


According to Table 3, it could be concluded that BNL had the values between 43.0-45.7 $\mathrm{dBA}$ and STI had the lowest value at 0.44 and the highest at 0.66 while the lowest RT value was at $0.61 \mathrm{~s}$ and the highest at $1.52 \mathrm{~s}$ when the PAS level was increased. As a result, the ambient noise level was decreased. This is consistent with the reverberation time. The STI was high which means that the clearness of speech communication became better.

When the experimental room area had the sound-absorbing surface at the amount of $30 \%$ of the entire area, it was clear that the indexes of the BNL, STI, and RT were close to the standard criteria, especially when RT was at 0.70 seconds which is considered in a standard range and when STI was in a 'good' level which is considered appropriate for a classroom.

In addition, when the Sound Pressure Level (SPL) was taken into consideration, it showed the same result as the BNL---the higher PAS, the lower the loudness. From this phenomenon, it could be further explained that the larger sound-absorbing area in the classroom, the lower level loudness can be perceived.

\section{FINDINGS}

The research results were divided into three parts as follows.

Part 1---This part illustrates the data analysis using descriptive statistics to analyze three main aspects of the auditory perception: the perceived loudness, the perceived clearness, and the perceived reverberation. The mean score of the students' satisfaction level towards the PAS after the PAS adjustment and the comparison between the science and the art students are presented.

Part 2---This part presents the statistical analysis of t-test in order to compare the mean score of the students' satisfaction on each aspect between the two groups to find out the statistically significant difference at a confidence level of $95 \%$.

Part 3---This part shows the comparison of the satisfaction between the two groups in choosing the classroom with five PAS level.

\section{Part 1: The Descriptive Statistics in Three main issues}

\section{The Perceived Loudness}

The results of the loudness perception level were classified into three groups; (1) the mean score of everyone's satisfaction (2) the mean score of the science student group and (3) the mean score of the art student group. 
Table 4

Mean score of the auditory perception of the students

\begin{tabular}{lcccccccccc}
\hline \multirow{2}{*}{ PAS } & \multicolumn{2}{c}{ All students $(n=107)$} & \multicolumn{3}{c}{ Science $(n=54)$} & \multicolumn{3}{c}{ Art $(n=53)$} \\
\cline { 2 - 11 } & $\begin{array}{c}\bar{x} \\
\text { loudness }\end{array}$ & $\begin{array}{c}\bar{x} \\
\text { clearness }\end{array}$ & $\begin{array}{c}\bar{x} \\
\text { reverb }\end{array}$ & $\begin{array}{c}\bar{x} \\
\text { loudness }\end{array}$ & $\begin{array}{c}\bar{x} \\
\text { clearness }\end{array}$ & $\begin{array}{c}\bar{x} \\
\text { reverb }\end{array}$ & $\begin{array}{c}\bar{x} \\
\text { loudness }\end{array}$ & $\begin{array}{c}\bar{x} \\
\text { clearness }\end{array}$ & $\begin{array}{c}\bar{x} \\
\text { reverb }\end{array}$ \\
\hline PAS 0 & 2.35 & 1.76 & $\mathbf{4 . 3 3}$ & 2.28 & 1.66 & $\mathbf{4 . 3 4}$ & 2.42 & 1.87 & $\mathbf{4 . 3 1}$ \\
\hline PAS 7.5 & 2.84 & 2.70 & 3.61 & 2.54 & 2.40 & 3.69 & 3.15 & 3.01 & 3.52 \\
\hline PAS 15f & 2.94 & 2.84 & 3.02 & 2.97 & 2.89 & 2.97 & 2.91 & 2.79 & 3.08 \\
\hline PAS 15b & 3.01 & 3.32 & 2.50 & 3.15 & 3.46 & 2.35 & 2.87 & 3.19 & 2.66 \\
\hline PAS 30 & $\mathbf{3 . 9 8}$ & $\mathbf{4 . 1 4}$ & 1.56 & $\mathbf{4 . 2 4}$ & $\mathbf{4 . 5 1}$ & 1.38 & $\mathbf{3 . 7 1}$ & $\mathbf{3 . 7 6}$ & 1.74 \\
\hline
\end{tabular}

Note. PAS=Percentage of Absorbing Surface

Table 4 indicates that the perception level was in contrast to the loud measuring by the equipment. When the PAS was high, the sound level of measurement was low. Conversely, the student perception increased according to the PAS level (PAS 30=76.02 $\mathrm{dBA}, \overline{\mathrm{x}}=3.98$; PAS $0=77.83 \mathrm{dBA}, \overline{\mathrm{x}}=2.35$ ). Same results of perception were found in both the science and art group. Both groups indicated that the highest sound level was in the room with PAS $30(\overline{\mathrm{x}} \mathrm{Sci}=4.24, \overline{\mathrm{x}} \mathrm{Art}=3.71)$ and they perceived the lowest sound level in the room with PAS $0(\overline{\mathrm{x}} \mathrm{Sci}=2.28, \overline{\mathrm{x}}$ Art=2.42) but there was a slight difference found in their perceptions. The science students indicated that the second degree level of sound loudness was when the room had PAS $15 \mathrm{~b}(\overline{\mathrm{x}}=3.15)$ while the art students selected the second degree level of loudness when the room had PAS $7.5(\overline{\mathrm{x}}=3.15)$. It can be concluded that science students were capable of perceiving a higher degree of loudness in the classroom with PAS over $15 \%$ while art students were capable of perceiving a higher degree of loudness in the classroom with PAS below $15 \%$.

\section{The Perceived Clearness}

In terms of the students' perception of the lecturing speech clearness, it was discovered that the loudness perception level was congruent with the measuring tool of STI (PAS $30=0.59$, PAS $0=0.48$ ). It means that when the classroom had more PAS level, it resulted in clearer lecturing sound.

The students' opinions about the clearness of sound they perceived. The classroom where they perceived the highest degree of sound clearness was the room with PAS 30 $(\overline{\mathrm{x}} \mathrm{Sci}=4.51, \overline{\mathrm{x}}$ Art=3.76), followed by PAS $15 \mathrm{~b}(\overline{\mathrm{x}} \mathrm{Sci}=3.46, \overline{\mathrm{x}} \mathrm{Art}=3.19)$ and the classroom with the lowest degree of round clearness was PAS 0 ( $\overline{\mathrm{x}}$ Sci=1.66, $\overline{\mathrm{x}}$ Art=1.87). There was a slight difference found between the results from science students and art students. The science students indicated that the sound in the PAS $15 \mathrm{f}$ room was clearer than the sound in the PAS 7.5. This result was contradictory to what the art students perceived.

\section{Perceived Reverberation}

As for the test on the perceived reverberation of the students, it was discovered that the students' perceptions were consistent with the measurement via the sound device. The classroom with more PAS resulted in lower perceived reverberation (PAS 30=0.69 
second, PAS $0=1.39$ second). Overall, the opinions of students in both groups are consistent. The perceived reverberation would be reduced when the classroom had higher PAS. The highest perceived reverberation classroom was PAS $0(\overline{\mathrm{x}} \mathrm{Sci}=4.34, \overline{\mathrm{x}}$ Art=4.31), followed by PAS $7.5(\overline{\mathrm{x}} \mathrm{Sci}=3.69, \overline{\mathrm{x}} \mathrm{Art}=3.52)$ and the room with the least perceived reverberation room was PAS 30 ( $\overline{\mathrm{x}} \mathrm{Sci}=1.38, \overline{\mathrm{x}} \mathrm{Art}=1.74)$.

Table 4 shows that most of the students' opinions are in agreement except a few differences. The mean score of the art group was a bit higher than the science group when the room had the PAS level of $15 \%$ or higher. On the other hand, the perceived reverberation of the science students was higher when the room had the PAS lower than $15 \%$.

\section{Part 2: The Difference Analysis between Two Groups by t-test}

According to the results from the descriptive statistics, it shows the difference in the opinions of both groups. In order to confirm the statistically significant difference, t-test was used to find out the mean score difference at a confidence level of $95 \%(* \mathrm{p}<.05)$. The research dependent variables: perceived loudness, clearness, and reverberation, were taken into consideration both overall and separately between two conditions of PAS: PAS-above $15 \%$ and PAS-below $15 \%$.

From Table 5, it indicates that in general, both groups had no difference of sound perception in all of the three aspects: the perceived loudness, the perceived clearness, and perceived reverberation. However, a slight difference was found when each aspect was carefully investigated. Data from art students shows that the mean score of reverberation perception was higher than the mean score of loudness and clearness while data from the science students shows that the mean score of the loudness and clearness perceptions were higher than the art students.

Table 5

Mean and Standard Deviation of satisfaction in overall the Science and the Art students

\begin{tabular}{|c|c|c|c|c|c|c|}
\hline \multirow{2}{*}{ Dependent variables } & \multicolumn{2}{|c|}{ Science group $(n=54)$} & \multicolumn{2}{|c|}{ Art group $(n=53)$} & \multirow{2}{*}{$t$-value } & \multirow[b]{2}{*}{$p$} \\
\hline & $\bar{x}$ & S.D. & $\bar{x}$ & S.D. & & \\
\hline Perceived Loudness & 3.13 & .32 & 3.06 & .32 & 1.073 & .286 \\
\hline Perceived Clearness & 3.14 & .39 & 3.01 & .34 & 1.791 & .076 \\
\hline Perceived Reverberation & 2.76 & .34 & 2.92 & .35 & -2.452 & .795 \\
\hline
\end{tabular}

${ }^{*} p<.05$ is the level of significance

However, when data was carefully analyzed separately between two conditions: The room with PAS above $15 \%$ and PAS below 15\%, the statistically significant difference in opinions was found as shown in Table 6 . The perceived loudness and the perceived clearness of the science group were higher than the perceived loudness and the clearness when the classroom had the PAS above $15 \%$. Meanwhile, the loudness and the clearness perception of the art students were higher when the classroom had the PAS below $15 \%$.

In terms of perceived reverberation in the classroom with the PAS below 15\%, findings from both groups showed no difference. However, there was the statistically significant 
difference in opinions between the two. The art students rated their perceived reverberation higher in the room with PAS15 \& PAS30.

Table 6

Mean and Standard Deviation of satisfaction when PAS was classified into two groups

\begin{tabular}{llllllll}
\hline \multirow{2}{*}{ Dependent variables } & \multicolumn{6}{l}{ Science group $(n=54)$} & \multicolumn{2}{l}{ Art group $(n=53)$} & \multirow{2}{*}{$t$-value } & $p$ \\
\cline { 2 - 5 } & $\bar{x}$ & S.D. & $\bar{x}$ & S.D. & & \\
\hline Perceived Loudness & & & & & & \\
- Classroom with PAS 0 \& 7.5 & 2.41 & .66 & 2.78 & 49. & $-3.354^{*}$ & .001 \\
- Classroom with PAS 15 \& 30 & 3.23 & .43 & 3.03 & .37 & $2.659^{*}$ & .009 \\
\hline Perceived Clearness & & & & & & \\
- Classroom with PAS 0 \& 7.5 & 2.03 & .58 & 2.44 & .48 & $-3.979 *$ & .000 \\
- Classroom with PAS 15 \& 30 & 3.42 & .54 & 3.14 & .46 & $2.855^{*}$ & .005 \\
\hline Perceived Reverberation & & & & & & \\
- Classroom with PAS 0 \& 7.5 & 4.04 & .57 & 3.91 & .50 & 1.005 & .317 \\
- Classroom with PAS 15 \& 30 & 2.38 & .43 & 2.66 & .44 & $-3.309 *$ & .001 \\
\hline
\end{tabular}

$* p<.05$ is the level of significance

Part 3: The Comparison of the Satisfaction of Both Groups in Choosing the Classroom with Five PAS Levels

The auditory perception analysis of the science and the art students reveals that their perceptions were different when the absorbing surface in the classroom was adjusted. Next, the participants were asked to evaluate the classroom by answering the question "Which is the most appropriate pattern of sound (PAS level) for a lecture classroom?".

Table 7

The comparison of the satisfaction of both groups in choosing the classroom

\begin{tabular}{|c|c|c|c|c|c|c|c|c|c|}
\hline \multirow{2}{*}{$\begin{array}{l}\text { Classroom } \\
\text { with PAS } \\
\text { (Percentage of } \\
\text { Absorbing Surface) }\end{array}$} & \multicolumn{3}{|c|}{ All student $(n=107)$} & \multicolumn{3}{|c|}{ Science group $(n=54)$} & \multicolumn{3}{|c|}{ Art group $(n=53)$} \\
\hline & Freq. & Pct. (\%) & Priority & Freq. & Pct. (\%) & Priority & Freq. & Pct. (\%) & Priority \\
\hline PAS 0 & 5 & 4.7 & & 1 & 1.9 & & 4 & 7.5 & \\
\hline PAS 7.5 & 36 & 33.6 & 2 & 1 & 1.9 & & 35 & 66.0 & 1 \\
\hline PAS $15 f$ & 0 & 0 & & 0 & 0 & & 0 & 0 & \\
\hline PAS 15b & 13 & 12.1 & & 10 & 18.5 & 2 & 3 & 5.7 & \\
\hline PAS 30 & 53 & 49.5 & 1 & 42 & 77.8 & 1 & 11 & 20.8 & 2 \\
\hline
\end{tabular}

In Table 7, it was evident that overall all students chose the classroom with PAS 30 to be a suitable classroom for lecturing, followed by the PAS 7.5 classroom. When the results from two groups were compared, it was found that their attitudes were different. The science students thought the PAS 30 was the most suitable $(77.8 \%)$ while the art students thought the PAS 7.5 was the most suitable (66.0\%). 20.8\% of the art students thought that the PAS 30 was suitable for lecturing.

Therefore, the findings signify that PAS 30 and PAS 7.5 classrooms were selected as a type of classrooms with two clear sound characteristics: deadly sound and lively sound. 
The classroom with PAS $7.5 \%$ was a type of lively sound which means it had the reverberation in the room ( $\mathrm{RT}=1.16$ second). The reverberation sound could enhance the sound distribution from the front to the back area of the classroom. In addition, the sound clearness level inside the room was at the moderate level $(\mathrm{STI}=0.54)$. As for the PAS 30 room (deadly sound), the room has the highest sound absorbing capability, had sound reverberation and clearness level conforming to the standard. That was the reason why the two room types had a different advantage. The deadly sound room benefits the sound clearness and reduces the reverberation sound and the ambient noise. On the other hand, the lively sound room would promote the emotional acoustics

\section{CONCLUSION}

This experimental research on the large classroom environment aimed to evaluate the auditory perception of the individuals with educational backgrounds. The sound perception consisted of three aspects: loudness, clearness, and reverberation were investigated. The research participants were the science and the art students divided in equal number. In the experiment, the room was adjusted the sound-absorbing capability or Percentage of Absorbing Surface (PAS) by setting 5 levels from30-0 \%. The participants were asked to evaluate the sound perception of each aspect through a questionnaire and the results were divided into three main parts; (1) result from the descriptive statistics (2) result from t-test; the difference analysis between the two groups (3) the evaluation of the suitability of the lecture classrooms).

Part 1---The results show that the participants' opinions on the three aspects of sound quality were consistent with the test results from a sound device. However, an opposite result found in one aspect: the loudness perception. As for the students' perception evaluation, overall the evaluations of all aspects from both groups are in line. That is a higher level of PAS in the room would decrease the loudness and the reverberation, and increase the clearness of the speech. However, the significant difference was found when the room with different PAS levels (the room with PAS above $15 \%$ and the room with PAS below $15 \%$ were compared).

Part 2---The t-test analysis was applied to analyze the significant difference at the confidence level of $95 \%$. From the overall analysis, it was found that the student's attitude had no difference in auditory perception. Nevertheless, when each of the PAS levels was separately investigated, difference significant difference was found in auditory perception of the students. It could be concluded that the science students perceived loudness and clearness better in the room with the PAS above $15 \%$. On the other hand, art students perceived loudness and clearness better in the room with PAS below $15 \%$. In addition, they also perceived reverberation better in the room with PAS above $15 \%$. However, in the room with PAS below $15 \%$, both groups showed no difference in the reverberation perception.

Part 3---The students were asked to indicate the most suitable condition for a lecture classroom. Most of the science students $(77.8 \%)$ chose the PAS 30 classroom and the PAS 30b classroom respectively while most of the art students $(66.0 \%)$ selected PAS 7.5 and the PAS 30 rooms respectively. 
Based on the findings, it can be concluded that the educational backgrounds affected the attitude and the sound perception of the students. This is because science students are keen on logical thinking while expressing emotions generally appeals to art students. These research findings shed some light on for the next in-depth research studies regarding psychological sound perception. It will also be beneficial to the field of acoustical designs when it comes to creating a physical classroom environment suitable for teaching and learning.

\section{REFERENCES}

ANSI-S12.60. (2002). American National Standard Institute-acoustical performance criteria, design requirements, and guidelines for schools. New York: Acoustical Society of America. $\quad$ Retrieved from http://www.soundivide.com/uploads/content_file/asa_acoustic_requirements_for_school s-50.pdf

Astolfi, A., Corrado, V., \& Griginis, A. (2008). Comparison between measured and calculated parameters for the acoustical characterization of small classrooms. Applied Acoustics, 69, 966-976 .http://doi.org/10.1016/j.apacoust.2007.08.001

Asutay, E., Vastfjall, D., Tajadura-Jimenez, A., Genell, A., Bergman, P., \& Kleiner, M. (2012). Emoacoustics: A study of the psychoacoustical and psychological dimensions of emotional sound design. Journal of the Audio Engineering Society, 60(1/2), 21-28. Retrieved from http://www.academia.edu/1650139

Bistafa, S., \& Bradley, J. (2000). Reverberation time and maximum background noise level for classrooms for a comparative study of speech intelligibility metrics. The Journal of the Acoustical Society of America, 107(2), 861-875. http://dx.doi.org/10.1121/1.428268

Bradley, J. (1986a). Predictors of speech intelligibility in rooms. The Journal of the Acoustical Society of America, 80(3). 837-845. http://dx.doi.org/10.1121/1.393907

Bradley, J. (1986b). Speech intelligibility studies in classrooms. The Journal of the Acoustical Society of America, 80(3). 846-854. http://dx.doi.org/10.1121/1.393908

Cabanaugh W, Wikes J (1998) Architectural Acoustics: Principles and Practice. New York: John Wiley \& Sons, pp. 21-22.

Egan, M. D. (1972). Concepts in Architectural Acoustics. New York, NY: McGraw-Hill Book Company

Fasanya, B. K., Bankole, K., Mcbride, Maranda, E., Regina, P. F., \& Celestine, N. (2011). Gender differences in auditory perception and computational divided attention tasks. Proceeding of the $41^{\text {st }}$ International Conference on Computer \& Industrial Engineering (pp. 241-247).

Fuchs, H., Zha, X., Zhou, X., \& Drotleff, H. (2001). Creating low-noise environments in communication rooms. Applied Acoustics, 62, 1375-1396. http://doi.org/10.1016/S0003-682X(01)00008-1 
Hodgson, M. (1999). Experimental investigation of the acoustical characteristics of university classrooms. The Journal of the Acoustical Society of America, 106, 1810. http://dx.doi.org/10.1121/1.427931

IEC 60268-16 (2011). Objective rating of speech intelligibility by speech transmission index (4th ed.). Geneva: International Electrotechnical Commission. Retrieved from https://webstore.iec.ch/publication/1214

Klatte, M., \& Hellbruck, J. (2010, June). Effects of classroom acoustics on performance and well-being in elementary school children: A field study. Paper presented at the thirty-ninth International Congress and Exposition on Noise Control Engineering, Internoise 2010, Lisbon, Portugal. Retrieved from http://www.spacustica.pt/internoise2010

Larm, P., Keranen, J., Helenius, R., Hakala, J., \& Hongisto, V. (2004, June). Acoustics in open-plan offices - A laboratory study. Paper presented at the Joint Baltic-Nordic Acoustics Meeting 2004 (pp. 2021-2025). Mariehamn, Aland. Retrieved from http://www.akustinenseura.fi/wp-content/uploads/2013/08/o15.pdf

Leeniva, P. \& Upala, P. (2015, June). Integration of psychoacoustics and activities in the learning environment. Proceedings of the European Network for Housing Research, ENHR 2015. Lisbon, Portugal. Abstract retrieved from http://www.enhr2015.com/images/residential_Buildingsd_v3.pdf

Leeniva, P. \& Upala, P. (2017a, January). Evaluation of sound absorption performance of large lecture rooms in public university. Proceedings of the International Symposium on Social Sciences and Management, ISSSM 2017 (pp. 366-377). Sapporo. Hokkaido: Higher Education Forum.

Leeniva P, Upala P. (2017b). Model of Thailand Speech Intelligibility (T-SI) in the large classrooms from public university. Asian Social Science, 13(7),69-82. https://doi.org/10.5539/ass.v13n7p

Olson, H. (1967). Music, Physics and Engineering. New York, NY: Dover Publications.

Paradis, R. (2014) Acoustic Comfort. Washington, DC: National Institute of Building Sciences, Whole Building Design Guide. Retrieved from https://www.wbdg.org/resources/acoustic-comfort

Sala, E., \& Viljanen, V. (1995). Improvement of acoustics conditions for speech communication in classrooms. Applied Acoustics, 45, 81-91. https://doi.org/10.1016/0003-682X(94)00035-T

Tang, S. K., \& Wong, C. T. (1998). Performance of noise indexes in office environment dominated by noise from human speech. Applied Acoustics, 55(4), 293-305. http://doi.org/10.1016/S0003-682X(98)00008-5

Tang, S. K., \& Yeung, M. H. (2003). Speech transmission index or rapid speech transmission index for classrooms? A designer's point of view. Journal of Sound and Vibration, 276, 431-439. https://doi.org/ 10.1016/j.jsv.2003.10.036 
Zannin, P. H., \& Marcon, C. R. (2007). Objective and subjective evaluation of the acoustic comfort in classrooms. Applied Ergonomics, 38, 675-680. http://doi.org//10.1016j.apergo.2006.10.001 